\title{
EM FOCO \\ DRAMATURGIA DA \\ EXPERIÊNCIA: CORPO, \\ AUTOBIOGRAFIA E FEMINISMOS \\ NA CRIAÇÃO DE NO TE \\ PONGAS FLAMENCA!
}

DRAMATURGY OF EXPERIENCE: BODY, AUTOBIOGRAPHY AND FEMINISMS IN THE CREATION OF NO TE PONGAS FLAMENCA!

DRAMATURGIA DE LA EXPERIENCIA: CUERPO, AUTOBIOGRAFÍA Y FEMINISMOS EN LA CREACIÓN DE NO TE PONGAS FLAMENCA!

\section{PATRICIA FAGUNDES}

JULIANA KERSTING

FAGUNDES, Patricia; KERSTING, Juliana.

Dramaturgia da experiência: corpo, autobiografia e feminismos na criação de No te pongas flamenca!

Repertório, Salvador, ano 24, n. 36, p. 164-189, 2021.1 


\section{RESUMO}

O artigo reflete sobre o processo de criação cênica e dramatúrgica de No te pongas flamenca!, espetáculo desenvolvido entre 2017 e 2019 como parte de pesquisa de mestrado da atriz e bailaora Juliana Kersting. Na montagem, repertório corporal, autobiografia e feminismos operam como fontes e provocações de uma narrativa que busca compor outras histórias, nossas histórias, distintas dos discursos do poder. Em intersecções entre teoria e prática artística, corpo e conceito, propõe-se uma dramaturgia da experiência feita de subjetividade, memória, desejo, processo, encontros e desencontros. Ao mesmo tempo que é feito de experiência, o próprio fazer cênico/ dramatúrgico é experiência, ou seja, o que fazemos nos faz e tece narrativas no mundo.

\begin{abstract}
The paper reflects on the scenic and dramaturgical creation process of No te pongas flamenco!, a play developed between 2017 and 2019 as part of the Master's research of the actress and flamenco dancer Juliana Kersting. In the montage, body repertoire, autobiography and feminisms operate as sources and provocations of a narrative that seeks to compose other stories, our stories, distinct from the speeches of power. At intersections between theory and artistic practice, body and concept, a dramaturgy of experience is proposed, made up of subjectivity, memory, desire, process and encounters. At the same time that it is made of experience, the scenic/dramaturgical work itself is an experience, that is, what we do makes us and weaves narratives in the world.
\end{abstract}

\section{RESUMEN}

El artículo reflexiona sobre el proceso de creación escénica y dramatúrgica de No te pongas flamenca!, espectáculo desarrollado entre 2017 y 2019 como parte de la investigación del Master de la actriz y bailaora Juliana Kersting. En la puesta en escena, el repertorio corporal, la autobiografía y los feminismos operan como fuentes y provocaciones de una narrativa que busca componer otras historias, nuestras historias, distintas de los discursos del poder. En intersecciones entre teoría y práctica artística, cuerpo y concepto, se propone una dramaturgia de la experiencia, compuesta de subjetividad, memoria, deseo, proceso, encuentros y desencuentros. Al mismo tiempo que está hecho de experiencia, el trabajo escénico /dramatúrgico en sí es una experiencia, es decir, lo que hacemos nos hace y teje narrativas en el mundo.

\section{Palavras-chave:}

teatro; dramaturgia; corpo; feminismos; autobiografia.

\section{KEYWORDS:}

theater; dramaturgy; body; feminisms; autobiography.

\section{Palabras clave:} teatro; dramaturgia; cuerpo; feminismos; autobiografía. 


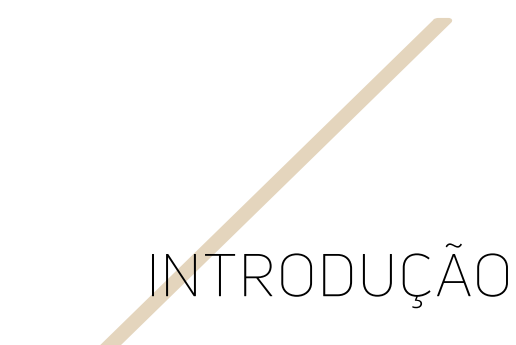

NoçõES E PRÁTICAS de dramaturgia são tão múltiplas como a diversidade de propostas e poéticas da cena contemporânea. Em diversas produções, não há um texto prévio que opere como matriz criativa; a dramaturgia é composta no processo de ensaios, junto a outros elementos cênicos. Este procedimento marca o fazer de grupos de renome e ressonância internacional, como os ingleses Forced Entertainment ou Cumplicite; nacional, como os paulistas Teatro da Vertigem e Núcleo Bartolomeu de Depoimentos; além de diversos grupos e coletivos que compõem a extensa trama do fazer cênico fora dos grandes centros ou dos focos de maior visibilidade, nacional ou internacional.

Este texto propõe uma reflexão sobre uma pesquisa cênica desenvolvida em Porto Alegre, cidade no sul do Sul do país onde, como em tantos lugares do mundo, diversas experiências de criação cênica envolvem a composição de dramaturgia original, tanto na universidade como na cena local, e em atravessamentos entre ambos contextos. Grupos como Teatro Sarcáustico, ${ }^{1}$ Cia Rústica de Teatro 2 e Cia de Flamenco del Puerto ${ }^{3}$ constituíram e constituem plataformas para experiências de composição dramatúrgica para diversos artistas da cidade, incluindo as autoras deste texto, que também dialogam com o contexto do Programa de Pós-Graduação em Artes Cênicas da Universidade Federal do Rio Grande do Sul
1 Grupo integrado pelos artistas Daniel Colin, Guadalupe Casal e Ricardo Zigomático. Ver: https:// teatrosarcaustico. blogspot.com/p/o-grupo-teatrosarcaustico-reuniu-se.html

2 Núcleo de criação cênica com mais de 15 anos de atuação, dirigido por Patrícia Fagundes. Ver: www.ciarustica.com

3 Escola e companhia de flamenco com 21 anos de pesquisa e trabalho continuados, conduzida atualmente por Daniele Zill e Juliana Prestes, da qual Juliana participou durante anos e continua colaborando. Ver: www.instagram. com/delpuertoflamenco www.facebook.com/delpuertoflamenco. Daniele Zill também realizou mestrado no Programa de Pós-Graduação em Artes Cênicas (PPGAC) da Universidade Federal do Rio Grande do Sul (UFRGS) desenvolvendo a dissertação Corpo del puerto: gesto flamenco no espetáculo Las Cuatro Esquinas (2017), com orientação da Profa. Dra. Suzane Weber. 
(UFRGS), onde outras pesquisas de mestrado e doutorado envolvem processos de criação de dramaturgia e reflexões sobre os mesmos. ${ }^{4}$

Práticas de criação de dramaturgia, em processo de ensaios, com frequência a afastam do estatuto de obra fechada, aproximando-a da condição de impermanência e interconexão próprio das artes cênicas, que acontecem sempre no entre: entre corpos, o espaço e o tempo, o eu e o nós, as palavras e as coisas, entre elementos que se friccionam, complementam, iluminam ou contradizem. Em seu artigo sobre dramaturgia em campo expandido, o pesquisador teatral espanhol José Sánchez define dramaturgia como um espaço de mediação:

Isto é dramaturgia: uma interrogação sobre a relação entre o teatral (o espetáculo/o público), a atuação (que implica o ator e o espectador como indivíduos) e o drama (ou seja, a ação que constrói o discurso). Uma interrogação que se resolve momentaneamente em uma composição efêmera, que não pode ser fixada em um texto: a dramaturgia está além ou antes do texto, se resolve sempre no encontro instável dos elementos que compõem a experiência cênica. (SÁNCHEZ, 2011, p. 19, tradução nossa)

No mesmo texto, Sánchez aborda a questão do relato ou narrativa, afirmando que a necessidade humana de contar histórias, atribuindo sentidos ao vivido, se faz especialmente urgente em nosso tempo. É importante considerar que a ficção, e o ato de ficcionar, são parte do real, assim como há sempre uma dimensão ficcional em uma narrativa, mesmo que trate de ' fatos reais' ficção e realidade se entretecem na produção de si mesmas, configurando-se mutuamente através de acordos sociais. Em tempos de disputa de narrativas, o autor reconhece 'um ativismo cultural que situa precisamente no contar histórias um modo de resistência contra a imposição de mitologias fabricadas nas indústrias hegemônicas'. (SÁNCHEZ, 2011, p. 16, tradução nossa)

Inseridas neste contexto, as práticas da dramaturgia contemporânea propõem a construção de narrativas através dos múltiplos elementos e meios que constituem a cena; tecendo organizações de experiências, sentidos, imagens e ideias em certo espaço-tempo. O “como" e as “formas” utilizadas para contar histórias 
são plurais, muito além de um modelo linear e fechado em si mesmo - não só

no campo das artes, mas também nas manifestações da indústria cultural e da grande mídia “informativa”, que continuamente produzem narrativas e sentidos. Neste campo de produção e disputa, identificamos a importância do fazer dramatúrgico, que implica a questão de quem conta a história, como e através de que recursos. Que histórias precisamos contar, e como? O “como” não remete a uma questão estritamente formal, pois compõe a própria história, é parte da narrativa.

Nas artes cênicas, o processo criativo desenvolvido durante o período de ensaios forja um espaço-tempo especial, um microterritório de sociabilidade e experiência no qual outras lógicas de pensamento são acionadas, justamente porque habitam o campo da experiência. Nos referimos à experiência no sentido proposto pelo filósofo catalão Jorge Larrosa, ou seja, como “[...] aquilo que nos passa, ou que nos toca, ou que nos acontece, e, ao passar, nos forma e transforma" (LARROSA, 2014, p. 28), uma palavra que segundo o autor não deve ser fechada em um conceito:

A experiência seria o modo de habitar o mundo de um ser que existe, de um ser que não tem outro ser, outra essência, além da sua própria existência corporal, finita, encarnada, no tempo e no espaço, com outros. E a existência, como a vida, não pode ser conceitualizada porque sempre escapa a qualquer determinação, porque é, nela mesma, um excesso, um transbordamento, porque é nela mesma possibilidade, criação, invenção, acontecimento. Talvez por isso se trata de manter a experiência como uma palavra e não fazer dela um conceito [...]. (LARROSA, 2014, p. 43)

Os processos criativos da cena, marcados por uma dimensão corpórea e relacional, apresentam o potencial de compor territórios temporários abertos à experiência, um espaço de passagem, indefinido e arriscado, que envolve um gesto de interrupção ao tempo cotidiano, e que requer "escutar aos outros, cultivar a arte do encontro" (LARROSA, 2014, p. 25), e que, como a experiência, “não se define por sua determinação e sim por sua indeterminação, sua abertura". (LARROSA, 2014, p. 44) Mesmo em um espetáculo solo, há sempre uma experiência compartilhada de criação, seja com artistas que ocupam outras funções ou com o 
espectador em sua presença imaginada. Assim, compor a dramaturgia durante os ensaios implica colocá-la neste território movediço, feito de encontros e desencontros, atravessado por turbulências e contaminações. Neste processo, a própria experiência do fazer cênico fica marcada na organização narrativa, o que favorece construções abertas, episódicas, não lineares e inclusive contraditórias, pois comportam falas diversas, ruídos, dúvidas, rastros e restos.

A partir da percepção da dramaturgia como uma experiência, uma interrogação, um movimento, uma organização narrativa e uma composição efêmera que se resolve no encontro, este trabalho propõe a reflexão sobre um processo específico de criação cênica, cuja dramaturgia foi desenvolvida durante o período de ensaios, em encontros e fricções entre corpo, memória e teoria. No te pongas flamenca! é um espetáculo teatral ${ }^{5}$ solo que articula narrativas biográficas com corporeidade e ritmos da dança flamenca, dialogando com propostas de teatro feminista, em intersecções entre produção teórica e artística, universidade e criação cênica. A montagem integra a pesquisa de Mestrado, desenvolvida no Programa de Pós-graduação em Artes Cênicas da UFRGS entre os anos de 2017 e 2019 pela atriz e bailaora ${ }^{6}$ Juliana Kersting, que além de estar em cena assina a dramaturgia. O registro do espetáculo está disponível no em nota.?

Este texto se propõe assim a pensar o processo criativo desde sua vivência. Uma das autoras é atriz do espetáculo, Juliana Kersting. A outra é encenadora, não desta montagem, mas de diversas outras, e professora orientadora da pesquisa, Patricia Fagundes. Como indica a artista pesquisadora Ciane Fernandes, entendemos que é no corpo que "a prática e a pesquisa acontecem, convergem-se uma à outra" (FERNANDES, 2014, p. 3), e a arte pode ser uma chave-mestra que articula modos de pensamento:

[...] a arte deixa de ser apenas um produto ou mesmo um processo a ser descrito, analisado e inserido em outros moldes (por mais abertos e dinâmicos que sejam), e passa a ser em si mesma o modo de (des)organizar discursos e métodos, bem como questionar a imposição de resultados quantitativos. Ou seja, a prática artística passa a ser a chave-mestra que acessa,

5 Ainda que reconheçamos a porosidade das fronteiras entre dança e teatro, e que o flamenco constitua uma presença decisiva na obra em questão, definimos a montagem como teatral pelo conjunto de referências, opções estéticas, procedimentos criativos e enfoques adotados.

6 A expressão bailaora, deriva da palavra bailadora, e denomina as artistas que dançam flamenco. A escotha por este termo, ao invés de bailarina por exemplo, evidencia a intenção de localizar um modo de arte e existência surgido na mistura de povos - gitanos, mouros, judeus - reunidos no sul da Espanha, onde compartilharam seus saberes e também condições sociais de marginalização.

7 Ver: https://youtu.be/ I3PIvr7yKYo. 
torna-se estagnado com seu excesso de regras e normatizações.

(FERNANDES, 2014, p. 2)

Tanto a pesquisa como a dramaturgia assumem como matéria o próprio corpo-memória da atriz-bailaora, que narra a si mesmo e às mulheres de sua família, nos desdobramentos de existências marcadas por experiências comuns a outras mulheres na sociedade patriarcal que vivemos. Junto ao corpo, a dramaturgia envolve a experiência do encontro, durante o processo investigativo/criativo, com pensamentos feministas e decoloniais. ${ }^{8}$ Perspectivas políticas e filosóficas da arte que passam a compor a narrativa e a carne da cena.

A enunciação em primeira pessoa, que marca a montagem, também se faz ocasionalmente presente neste artigo, em fragmentos da dramaturgia textual e de reflexões pessoais da atriz (destacadas do corpo do texto, em itálico). Assumir a subjetividade revela a intenção, política e artística, de propor contrapontos à lógica do universal, objetivo e impessoal, que afirma um sistema "que reflete os interesses políticos específicos de uma sociedade branca colonial e patriarcal", como analisa a intelectual e artista Grada Kilomba (2016) na palestra-performativa Descolonizando o conhecimento. Ou seja, a intenção de reivindicar aquilo que habita o campo da experiência, aquilo que, de acordo com Larrosa, “[...] tanto a filosofia como a ciência tradicionalmente menosprezam e rechaçam: a subjetividade, a incerteza, a provisoriedade, o corpo, a fugacidade, a finitude, a vida". (LARROSA, 2014, p. 40) Acreditamos que a aventura de buscar epistemologias próprias das artes cênicas, que frequentemente escapam à lógicas cartesianas, encontra a urgência apontada por tantos estudos e propostas contemporâneas de romper com narrativas hegemônicas para compor outras histórias, nossas histórias, distintas dos discursos mais ou menos visíveis do poder.

Para pensar as tramas do processo criativo, esse acontecimento fugidio e resistente a categorizações, identificamos três campos/fontes de experiência que alimentaram a dramaturgia e pautaram questões da narrativa desenvolvida: corpo-memória, autobiografia e feminismos. Inicialmente enfocamos o repertório corporal como matéria dramatúrgica, que na montagem em questão se materializa no flamenco e, no eixo seguinte, desenvolvemos a questão da autobiografia. Finalizamos com
8 Não discutiremos aqui as diferenças conceituais propostas entre o descolonial e o decolonial, questão que foge ao escopo deste artigo. 
considerações a respeito dos discursos feministas como provocações transforma-

doras e definidoras de caminhos no processo de criação de No te pongas flamenca!. Tal divisão é apenas um recurso para estruturar a reflexão, pois estes campos ou fontes não operam isoladamente, e sim funcionam em ciclos de retroalimentação, compondo zonas de fronteira, onde se confundem e misturam. Entendemos que a dramaturgia é em si mesma uma zona fronteiriça e porosa, feita de tudo que a experiência da cena organiza e desorganiza, destrói e inventa, afirma e duvida, feita de corpo, palavra encarnada, movimento, espaço, tempo, experiência.

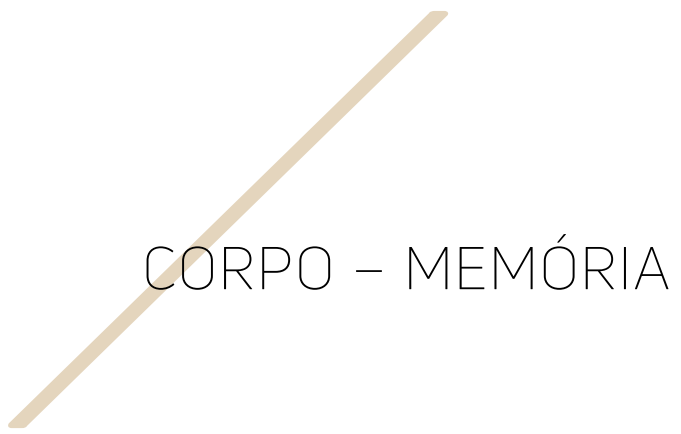

O corpo, e as relações que compõe com outros corpos, com o espaço e o tempo, constitui matéria basilar das artes cênicas. Mesmo em tempos de pandemia e distanciamento social, no qual tantas propostas de artistas cênicos se fazem mediadas por telas e programações digitais, o corpo é matéria de criação. Escreve, pensa, debate-se, procura, reescreve-se, narra-se. É um arquivo vivo e movediço de experiências, em contínua transformação, como ressalta a pesquisadora teatral alemã Fischer-Lichte (2008, p. 92):

\footnotetext{
O corpo humano não conhece o estado de ser, só existe no estado de devir. Recria a si mesmo a cada piscar de olhos, cada respiração e movimento incorpora um novo corpo. Por esta razão, o corpo é, ao final, elusivo. O estar-no-mundo corporal, que não pode ser mas é continuamente devir, veementemente recusa todas as noções de obra de arte. [...] Ao invés disso, o ator atravessa processos de incorporação. Através destes processos, o corpo é transformado e recriado - o corpo acontece.
}

O corpo acontece, é transformado e recriado na cena, permanecendo elusivo e incontrolável. Ao mesmo tempo, é feito de memória, como já nos disse Grotowski: “não é que o corpo tem memória. Ele é memória”. (GROTOWSKI, 2010, p. 173) 
A atriz-pesquisadora Tatiana Cardoso acrescenta a coexistência de tempora-

lidades, pois “Se corpo é memória, memória para mim, é a duração das experiências no corpo, que podem estar constantemente se atualizando". (CARDOSO, 2009, p. 29) Segundo a encenadora Anne Bogart, “o ato da memória é um ato físico e está no cerne da arte do teatro. Se o teatro fosse um verbo, seria o verbo ‘lembrar’”. (BOGART, 2011, p. 30) Para a referencial coreógrafa Pina Baush, a memória era um elemento central do processo criativo e da própria dramaturgia de suas obras, que entretecem lembranças, desejos e corpos, como já destacaram diversas pesquisadoras brasileiras, entre elas Solange Caldeira, ao afirmar que “a memória é, com certeza, o mais forte elemento articulador" dos temas abordados pela artista. (CALDEIRA, 2010, p. 121)

Esse corpo-memória, que carrega experiências e se transforma continuamente, feito de tempo e carne, que lembra como ato físico, é também matéria constitutiva da dramaturgia de No te pongas flamenca!. Tanto pelas narrativas biográficas, que partem da memória da atriz, e, portanto, estão inscritas no seu corpo, como pelo repertório de técnicas e práticas corporais que assume o papel de elemento narrativo, fusionando-se, reforçando, contrapondo ou ocupando possíveis lugares do texto na composição dramatúrgica. No corpo de Juliana, o flamenco é memória e prática de vida desde a adolescência; um lugar em que, batendo firme com os pés no chão, pode inventar narrativas de si, além das expectativas sociais e familiares.

Mais tarde, o teatro oferecerá à artista outro campo de experiência e construção, também ligado à prática corporal, inicialmente bastante referenciado pela Antropologia Teatral, e depois ampliado para outros modos de criação teatral. No flamenco e no teatro, possibilidades de narrar-se, de criar a partir do corpo, separados como linguagens e práticas do cotidiano, mas reunidos na experiência de vida.

Carrego uma percepção aguda de que a mistura entre os dois pode ser muito rica, sem que seja categorizada como dança-teatro ou teatro coreográfico. A corporeidade do flamenco é carregada de passado, de múltiplos corpos e povos que o constituíram e seguem o fazendo existir, atualizando-se e mesclando-se a outras linguagens artísticas. 
Os pés que batem no chão, sapateiam, e repercutem no corpo, exigindo, chamando, conferindo presença ao corpo que golpeia. O golpe, que é som, produz ritmo, faz música com o corpo. E, também, incomoda, desacomoda. Pressiona, percute, bate com e como o coração. Compasso. Descompasso. Precisão. Encontro. Encarna e treme a carne. Barulha, acaricia, chicoteia, ponteia, empurra, puxa. Som, silêncio e pausa preenchem o espaço. Pulsa, invade, arrebata, toca, comove, acalenta, seduz. O tronco carregado de oposições. O abdômen pressionado que sustenta as costas e dá equilíbrio, os ombros que buscam relaxar. Não se baila com tensão. Braços em movimento. Mãos que circulam com delicadeza em torno do pulso, dedilham, espalmam, agarram o ar. A corporeidade composta por estes cruzamentos todos, soma-se a música, a guitarra e o cante. Tons, maiores ou menores, andamentos variados, voz que parece um lamento, ou uma provocação, ou um convite. O movimento da música compõe o movimento da coreografia e vice-versa. Expande, contrai, ralenta, pontua. Uma troca, uma escuta constante em cena, em jogo. Ole tu, ole tu arte! Ole los buenos artistas! Toma! A emoção surge num instante, num verso, num toque da guitarra, em um trêmulo. Potente e suave e explosivo e alegre e triste e nostálgico ao mesmo tempo. É reboliço, rebordosa, casa cheia. Assim sinto o flamenco acontecendo em mim.

\footnotetext{
Figura 1: Pré-estreia No te pongas flamenca!, 23 de maio de 2019 Fotógrafa: Adriana Marchiori.
}

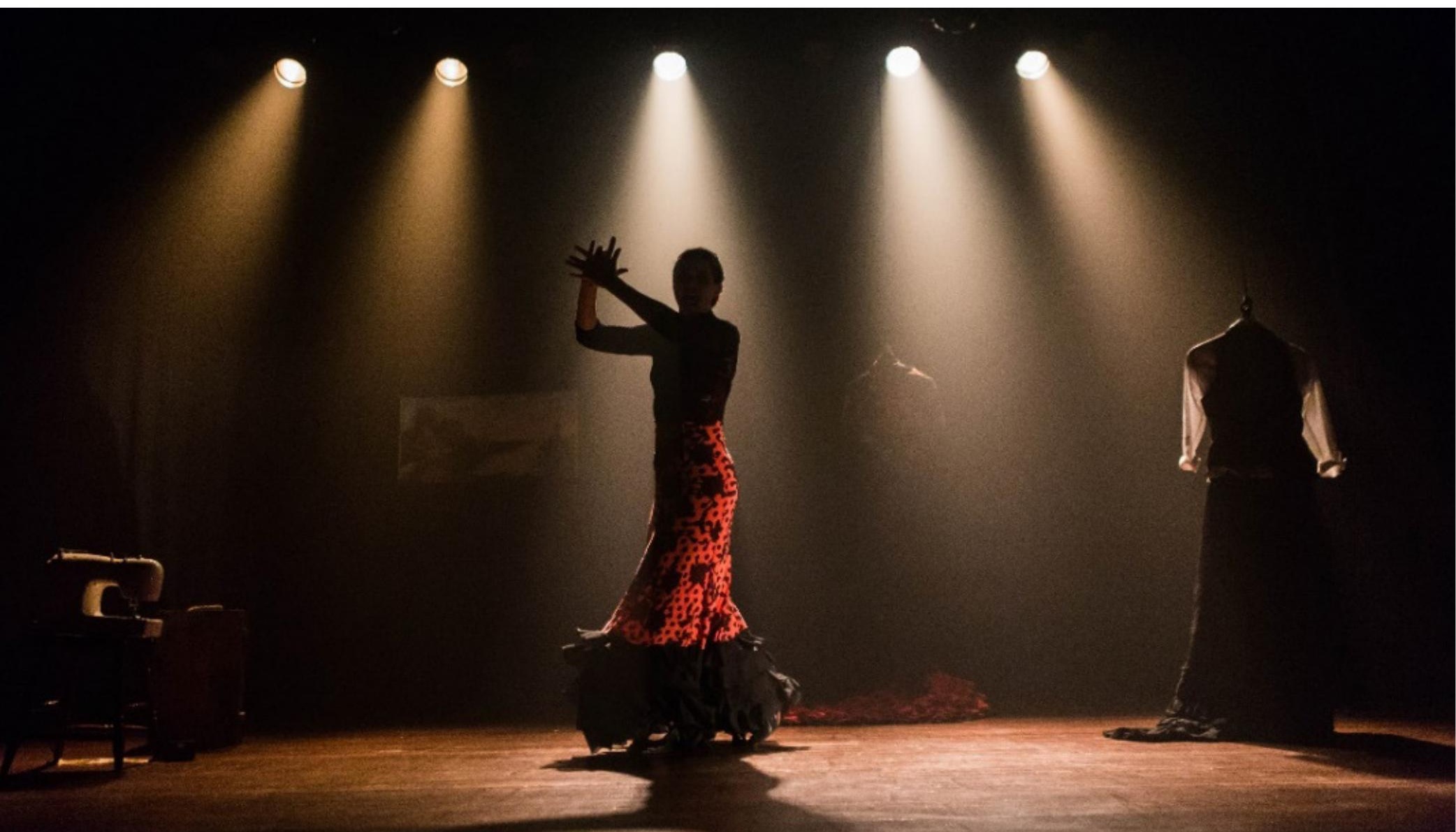


A antropóloga espanhola Cristina Cruces Roldán identifica quatro fontes funda-

doras do flamenco: “cultura musical e manifestações estéticas - baile; origem sociais e de classe; la copla, versos das músicas transmitidos pela tradição oral; e a sociabilidade e a ritualidade flamenca - a festa". (FER..., 2013) Para Roldán, em todas estas fontes a relação com o corpo é uma chave crucial, vinculada ao contexto histórico-social onde o flamenco se originou.

Sem esquecer o que é mais barato, móvel. O instrumento fundamental do flamenco, o corpo, que é grátis! Toda a percussão que pode ser feita com palmas, com pitos (estalo de dedos), que se pode fazer com os pés, se pode fazer com as pernas, a dança. Todo um povo pobre, todo ele um marco de uma sociedade do século XIX, assolada por uma pobreza que foi, a que origina, a que explica muitos dos elementos da música e do baile flamenco. (FER...,2013)

A noção de corpo como "instrumento" não corresponde ao campo conceitual deste trabalho, já que entendemos corpo como algo que acontece e está sempre em relação. No entanto, a ideia de um “corpo grátis” se encontra com a experiência do fazer teatral independente no Brasil, onde o principal recurso criativo também é humano e corpóreo. Como o flamenco, o teatro é feito de misturas, de corpos e desejo; multiplicidades de tempos e espaços reunidos em um momento fugaz, compartilhado entre corpos e redes de memórias. Um dos pontos de partida fundamentais para a criação de No te pongas flamenca! residiu no desejo de investigar trânsitos e diálogos entre teatro e repertório flamenco na composição cênica, articulando poeticamente o que já estava misturado no corpo da atriz.

Chego ao programa de pós-graduação para finalmente mergulhar nesta mistura que há tanto tempo desejo, teatro e flamenco, evocando as figuras da mãe, da rainha e da guerrilheira para abordar questões relacionadas a ser mulher. Foram 14 anos longe da universidade, sinto-me intimidada e confusa. Após os primeiros ensaios, dois caminhos surgiram como possibilidades de criação: o primeiro baseado em um trabalho de técnica corporal, misturando Laban e flamenco; o segundo movido pelo desejo de falar sobre o meu corpo grande, inadequado, sobre minha mãe e avó e sobre minha relação com a maternidade. Mas ambos estavam distantes 
do que eu imaginava como cena, o primeiro muito formal e o segundo sem flamenco. Sinto-me perdida. Decido que preciso de uma temática para materializar, algo que me provocasse, instigasse, apaixonasse. Eu queria falar de mulher, mas o que exatamente? O tema sempre esteve comigo. Meu corpo grande e incomodado; as mulheres da minha família e o meu encantamento por elas; minha filha e o tanto que transformou a minha vida, de tantas maneiras diferentes, todos os dias.

Esse sentir-se perdida, intimidada ou confusa é, de diversos modos, parte do processo criativo, onde nos colocamos em desequilíbrio para criar, nos aventuramos em territórios desconhecidos para compor histórias que estão em nós, mas ainda não sabemos. Tal condição nos aproxima, novamente, da perspectiva da experiência, onde “[...] o que se descobre é a própria fragilidade, a própria vulnerabilidade, a própria ignorância, a própria impotência, o que repetidamente escapa a nosso saber, ao nosso poder e à nossa vontade". (LARROSA, 2014, p. 42)

Como comecei? Como assim, vou ter que escrever a dramaturgia? Quais procedimentos e técnicas vou usar? Por que ensaiar sozinha é tão difícil? Lembro de programar ensaios e de não conseguir cumprir à risca o que propus. Lembro de parar para anotar no diário de ensaios e parecer que estava escrevendo sobre outra coisa, diferente da que acabei de fazer. Lembro de ficar muito excitada com uma cena nova e me sentir um fracasso e vazia quando não produzia nada. Lembro de teimar comigo mesma nos momentos em que duvidei da proposta de pesquisa (afinal quem inventou isso fui eu. Minha mãe diria, 'quem mandou inventar, agora aguenta!'). Lembro de desistir e depois retomar. Lembro de insistir até a cena surgir. E lembro de dizer a mim mesma para não julgar e me entregar ao momento. Tento me organizar nesse exercício de narrar-se. Escrever é inventar a si mesma. Deve ser por isso que as vezes é tão cansativo. Revivo os momentos, refaço-me num processo de questionamento e (re)criação constantes.

Em No te pongas flamenca!, o flamenco é também uma narrativa de si, na qual a artista se refaz e recria; mergulhando no desafio de articular uma composição não ilustrativa ou isolada, liberta da preocupação com modelos "corretos", recriando-se na mistura, na incorporação plural. Assim, o flamenco se oferece 
no processo como arquivo do corpo, material narrativo incrustado na pele, bem como repertório técnico basilar, oferecendo recursos para aquecimento, sequências corporais, ritmo para enunciação de textos, criação de imagens, percussão corporal. Durante o processo, vai entretecendo a dramaturgia, em sonoridade, corporeidade, estados energéticos que produzem sentidos, imagens, referência de figurinos, trilha sonora, e também como coreografia, movimento que é narrativa. Não há o uso do flamenco como fonte de signos, ou a intenção de significação de movimentos, objetos ou gestos, e sim uma aproximação afetiva e mnemônica que entrelaça imagens, música, dança, palmas; o corpo-memória da atriz em possíveis diálogos com as muitas memórias ancestrais que compõem esta arte de origem popular. Uma origem que se renova e atualiza continuamente, pois o flamenco continua existindo além dos grandes circuitos da arte, sendo dançado por pessoas anônimas, mulheres e homens, senhoras e crianças, em pequenos pueblos da Espanha e inclusive aqui, no sul do Brasil.

Uma tradição móvel e deslizante, multi-identitária. A percepção dos muitos corpos não-hegemônicos que compõem o flamenco. E por fim, eu: uma brasileira, que dança, canta e toca palma para si mesma enquanto diz textos e conta histórias sobre mulheres de sua familia, descendente de poloneses e alemães. Exerço minha autonomia como artista articulando os capitais culturais que carrego. Desta forma, o flamenco é vestido e logo despido, de traje e música. Eu, corpo -memória-atriz-bailaora.

Durante o processo, bailaoras como Pastora Galván e Melissa Calero ${ }^{10}$ ofereceram fontes de inspiração e referência dançante, em seus movimentos que entretecem tradição e contemporaneidade. Pastora Galván busca dialogar com a forma de bailar das senhoras do tradicional bairro de Triana, em Sevilha, evocando imagens de corpos não hegemônicos na dança, na memória de seu povo e através de seu próprio corpo. Melissa Calero baila ao som da voz da bailaora Carmen Amaya, um ícone da cultura flamenca que, na primeira metade do século $\mathrm{XX}$, dominava passos que eram reservados aos bailaores, cantava e bailava ao mesmo tempo, com frequência dançando de calças. Melissa também inspirou Juliana na aventura de sapatear e enunciar textos simultaneamente. Outras inspirações para a montagem foram as bailaoras Olga Pericet, Belén Maya, La Choni e a performer Pilar Albarracín.

9 Homenagem de Pastora Galván a Triana Pura. Ver: https://www. youtube.com/wat$c h ? v=5 \_b 2 A h Q 0 Z b Q$

10 Melissa Calero em La Huella. Todos somos Carmen Amaya. Ver: https:// www.youtube.com/ watch?v=K3uZ9niQwag. 


\section{AUTOBIOGRAFIA}

A criação a partir de material biográfico é um recurso bastante recorrente na cena atual, articulando-se de modos diversos, de maneira que não há um estilo cênico/dramatúrgico específico que envolva este tipo de produção. Ainda assim, é importante considerar que, mesmo em um solo autobiográfico, o foco não está em histórias privadas, pois não é o eu isolado que “fala”, mas sua relação com outro. Ao trabalhar-se com as próprias memórias e perspectivas, ao oferecerem-se testemunhos, podem-se acionar as vivências de quem assiste, atualizando-se o vivido, nesse espaço virtual entre o palco e a plateia onde se dá o teatro. Ou seja, a experiência do eu constrói-se em relação ao outro, o sentido faz-se no entre, no qual o individual é também social. Essa ampliação da experiência, a partir do ato de compartilhar, não elimina sua singularidade, que escapa à universalismos e pode articular narrativas distintas às do poder hegemônico, como destaca Patrícia Fagundes (2019, p. 29):

\footnotetext{
A perspectiva biográfica e suas micro-histórias oferecem a possibilidade de verdades transitórias e localizadas, experiências específicas que podem ser associadas pelo espectador às suas próprias experiências, fugindo de narrativas absolutas. Podemos pensar que toda arte é autobiográfica em alguma medida, já que é articulada a partir das experiências de vida de quem cria. Tem cor, gênero, sexo, classe, trajetória....Nesse sentido, dialoga com a noção de 'lugar de fala', que evidencia a condição social-individual de quem articula narrativas, desconstruindo a possibilidade de imparcialidade ou universalidade.
}

Pensar a questão do lugar de fala foi um disparador importante no processo de No te pongas flamenca!, a partir do encontro com o feminismo negro, que expõe o universalismo do termo "mulher" - de que mulher falamos ao falar de “mulher”? Em sua proposta de enegrecer o feminismo, Sueli Carneiro (2019, p. 314) questiona: “Quando falamos de romper o mito da rainha do lar, da musa idolatrada dos poetas, de que mulheres estamos falando? As mulheres negras fazem parte de um contingente de mulheres que não são rainhas de nada [...]". 
Kilomba (2016, p. 8) critica a posição privilegiada da branquitude que se coloca como norma não nomeada, como "um centro ausente, uma identidade que se coloca no centro de tudo, mas tal centralidade não é reconhecida como relevante, porque é apresentada como sinônimo de humano". A ação de localizar-se, de assumir uma experiência e um ponto de vista específicos, afirmou-se como necessidade fundamental em um processo de criação que foi atravessado pela urgência da reflexão crítica sobre a branquitude.

Sou sudaca, branca, mulher cis, mãe, artista e pesquisadora. Parto de um
lugar de privilégio, ocupo um espaço em um programa de pós-graduação
em uma universidade pública e sou bolsista. Nos interstícios de mulher
branca e latina, desperto meu olhar e escuta para as muitas e diferentes
formas de opressão impostas. Observo-me cada vez mais e começo a exer-
citar o meu lugar fala como lugar de escuta e também de 'cala'. Calar não
como uma violência ou resignação, mas uma atitude de respeito, atenção e
afetividade. Como dizia minha avó, a Olga, 'temos duas orelhas e uma boca'.

O lugar de fala, que é também lugar de escuta, remete ao campo do trabalho sobre si e ao encontro, fundamentais no processo criativo em questão, que toma como matéria o corpo-memória da atriz-bailaora em encontro com o outro e com o mundo. O encontro, neste sentido de existir em relação ao outro e ao mundo, é o movimento que permite a própria percepção de si, ao mesmo tempo que revela a realidade como uma narrativa produzida, que depende de acordos sociais, ou seja, muito distante da fantasia de uma verdade objetiva universal. A criação autobiográfica reconhece que memória é também imaginação, que narrar-se é ficcionar-se, e, portanto, nada “é porque é e sempre será assim”. A artista e pesquisadora Celina Alcântara, em sua tese sobre formação teatral como possibilidade de criação e transformação de si, afirma que “um corpo capaz de produzir ficção é um corpo que se transformou, que traz em si as marcas psicofísicas de uma caminhada; ou seja, é um corpo que também se ficcionou". (ALCÂNTARA, 2012, p. 52)

Experimento durante o processo a percepção de que sou ficção, de que somos ficção, e através do encontro reconheço que sou real. Permito-me navegar nestas histórias, entre a ficção e o real, e em seus interstícios produzir, ou revelar, narrativas. Sou eu e não sou eu ao mesmo tempo. Não existe 
a construção de personagens ficcionais. Falo em primeira pessoa, todavia, compartilho histórias pessoais e lembranças que passaram por uma construção e edição que compôs o texto do espetáculo. Há verdade nos fatos, porém subjetivados por mim e sem a preocupação de agregar indícios de verdade além de fotos e do ato de recordar e conversar com minha mãe sobre alguns acontecimentos. São ficções reais. Desta forma, possuem outras versões, concebidas entre o lembrar e o esquecer e o subjetivar das mulheres que trago ao palco. Sei que existo, porque o outro existe. O que me faz real é o encontro. Corpo, memória, encontro, carne e ficção.
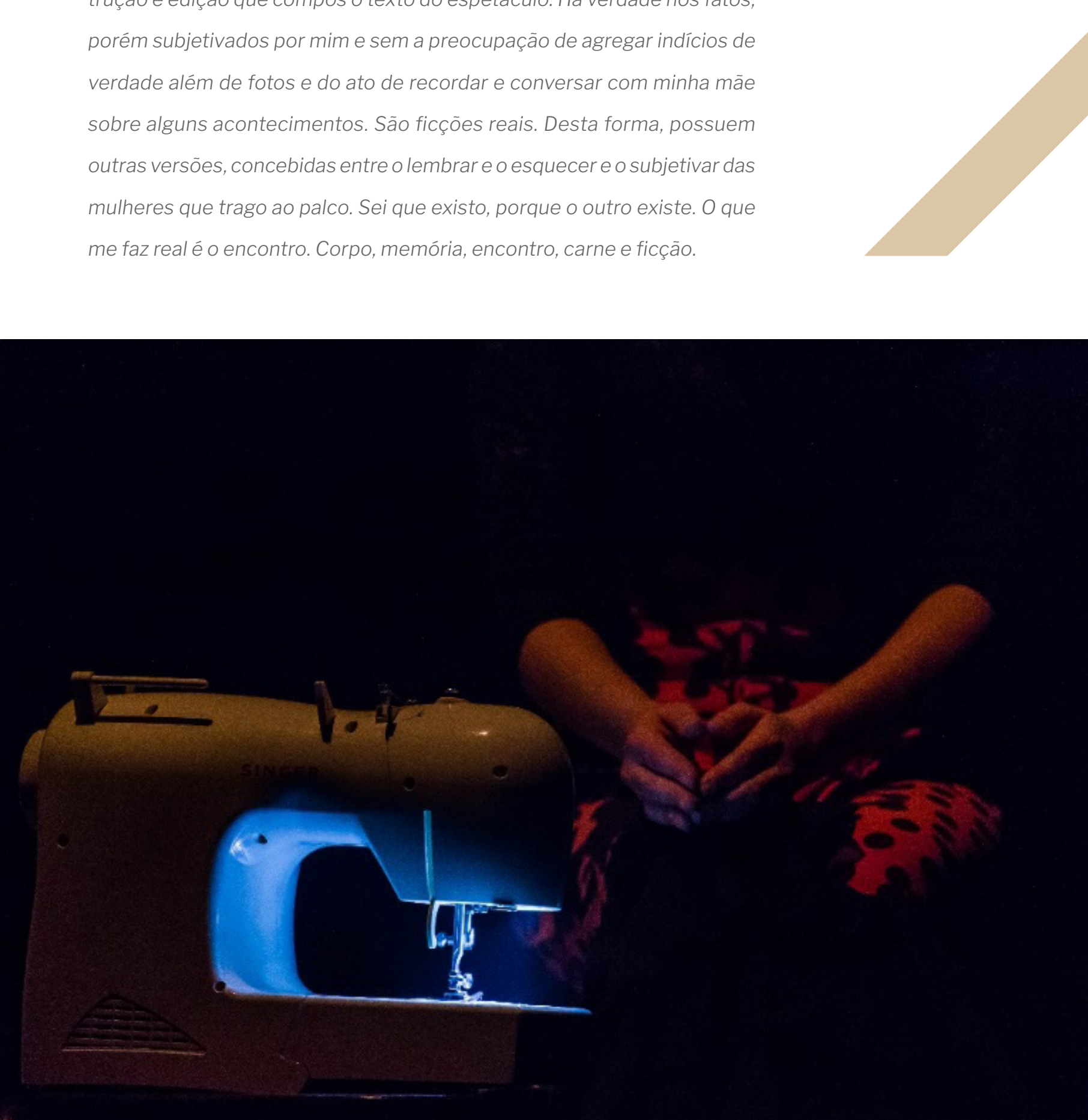

Figura 2: Pré-estreia No te pongas flamenca!, 23/05/2019 Fotógrafa: Adriana Marchiori. 
As histórias pessoais vão entretecendo a dramaturgia, a partir de memórias da atriz sobre suas experiências de vida e das mulheres de sua família - mãe, avós e tias - que viviam em uma pequena cidade de imigração polonesa no interior do Rio Grande do Sul. Existências marcadas por silenciamento, invisibilidade, resignação, contradições e revoltas. Memória de corpos que enfrentaram dificuldades em existir por serem mulheres. Ontem e hoje: corpos objetos, clandestinos, vulneráveis. E também rebeldes. Corpos políticos carregados de narrativas, que aparecem no texto e em outros componentes cênicos, como no quadro pintado pela avó, na máquina de costura que era instrumento de trabalho da família. Além das histórias, narradas às vezes na terceira pessoa, a estrutura de depoimento pessoal marca a dramaturgia, como na fala final, que é enunciada ao ritmo de palmas e dos pés que batem no chão e repercutem no corpo, na batida do flamenco em sua fúria e ternura:

Mulher cis. Branca, $1 \mathrm{~m} \mathrm{85,80} \mathrm{kg,} \mathrm{olhos} \mathrm{verdes,} \mathrm{posso} \mathrm{dizer} \mathrm{que}$ bonita. Não sou? Mãe de uma menina cis, apesar de três gravidezes. Artista. Nunca fui boa jogadora de basquete ou vôlei. Nem magra o suficiente para ser modelo/manequim. Tornei-me bailaora e atriz. "Você se mexe bem para alguém do seu tamanho'. Padrão. Não padrão. Depende do ponto de vista. Bom, de qualquer forma digo que a temperatura aqui em cima é a mesma que aí embaixo, ainda que o ar seja um pouco mais rarefeito, e sim, posso alcançar para vocês os objetos das prateleiras mais altas e depois trocar a lâmpada queimada. Namorei homens baixos, 1m68, e altos, 1m97. Fui motivo de deboche. Danem-se. Bailarina e atriz, deve ser puta. Separada com uma filha morando na capital, deve ser puta. E por que não? Danem-se. Fumante. Bebo, nem sempre socialmente. Solteira. Usuária continua de cafeína, cloridrato de bupropiona, oxalato de escitalopram. Eventualmente, mizoprostol, paracetamol, pantoprazol, dipirona monoidratada, citrato de orfenadrina e clonazepam, glúten, açúcar, gordura vegetal, emulsificantes monoglicerídeos, lecitina de soja, gordura anidra de leite, poliglicerol polirricinoleato e aromatizantes. Sim, aromatizantes. Sou uma mulher cheirosa e doce. Mas nem sempre. Meu corpo me apresenta e fala por mim. Vivo num rolo compressor de ansiedade, entre prazer e 
frustração. Um corpo com o sexo, o prazer controlado e mani-

pulado. Corpo clandestino, corpo objeto, corpo vulnerável, corpo rebelde. (KERSTING, 2019, p. 174)

\section{FEMINISMOS}

Como já indicado, o encontro com teorias feministas foi fundamental no processo criativo de No te pongas flamenca!, desacomodando certas perspectivas e agenciando outras. Uma experiência de estudo, debate e reflexão que afetou a vida e a prática artística da atriz, gerando curtos-circuitos criativos, que contaminaram a criação cênica e dramatúrgica. Corpo, autobiografia e feminismos se associam como provocações estruturantes do processo, intimamente relacionados na composição de uma narrativa que busca questionar lógicas heteropatriarcais.

Segundo Simone de Beauvoir (1980, p. 30) “toda história das mulheres foi escrita pelos homens" e, "portanto, está sob suspeição" completa Maria Amélia Telles (1999, p. 11). Assim, reescrevê-la é ir contra a hegemonia de uma sociedade masculina, branca e cisgênera. É tomar autoria de si, corpo-memória-subjetividade. É produzir contradiscursos, que com frequência se produzem a partir de nossas (her)stories, neologismo cunhado pela escritora e ativista estadunidense Robin Morgan (1960) com o objetivo de provocar a aparente neutralidade da linguagem. Ao trocar o pronome na palavra (his)story, história deles, por (her)story, história delas, Morgan propõe o fomento, a produção e o reconhecimento de narrativas de mulheres. Tal termo foi adotado pela pesquisadora e professora Maria Brígida de Miranda (2017) ao relatar práticas cênicas e ativistas produzidas por mulheres no curso de Teatro da Universidade do Estado de Santa Catarina (UDESC), indicando "o florescimento e amadurecimento de uma profusão de experimentos teatrais que se inserem no campo de estudos e produção artística feminista", em ações que "não estão isoladas, elas dialogam, reverberam e proliferam outros artivismos". (MIRANDA, 2017, p. 4) Ao se referir à produção de teatro feminista, Miranda afirma: 
O teatro feminista pode ser um dos principais veículos de comuni-

cação de ideias feministas, um espaço ficcional onde a força está na presença física das atrizes e nas narrativas teatrais ancoradas nas experiências de mulheres; em seus corpos vivos e pulsantes que criam imaginários de igualdade e empoderamento feminino. Essa presença cênica encarnada e sem mediação tem o potencial de criar uma comunhão entre mulheres, entre atrizes e espectadoras dispostas a inventar existências que denunciam, resistem e destroem o sistema patriarcal. (FABRINI; MIRANDA; ROMANO, 2018, p. 1)
A aproximação ao imaginário de um teatro feminista aconteceu durante o processo criativo de No te pongas flamenca!, através da experiência de conversas, leituras, aulas, debates, seminários, congressos, trocas; na percepção da profusão de produções teatrais que se relacionam à uma perspectiva feminista. Nesse sentido, o fluxo criativo da montagem também foi alimentado por trabalhos de colegas, amigas, parceiras que dialogam diretamente com material biográfico e discursos feministas: Vida alheia, da atriz pesquisadora Mariana Rosa, ${ }^{11}$ e Todas nós, da atriz pesquisadora lassanã Martins, ${ }^{12}$ ambos desenvolvidos no mesmo programa de pós-graduação; (E)terno e pílula da visibilidade: Maria Scariot Presente! da atriz e encenadora Stefanie (Tefa) Polidoro, ${ }^{13}$ sendo o primeiro sua pesquisa em graduação no DAD /UFRGS e o segundo de Mestrado no Programa de Pós-Graduação em Teatro (PPGT/ UDESC). Trabalhos que conectam pesquisa e criação cênica, corpo e conceito, arte e política. Pensar o mundo além da lógica patriarcal inclui a valorização da experiência compartilhada, do próximo, das redes de troca e afeto, que muitas vezes definem o próprio fazer teatral.

A artista pesquisadora Verônica Fabrini afirma que o teatro seria um espaço privilegiado para a prática de epistemologias feministas, pois é “[...] o lugar onde se é necessário multiplicar os olhares. No contexto atual brasileiro é urgente assumir esta causa em profundidade". (ALMEIDA, 2019, p. 1) Uma urgência de nosso tempo: articular outras narrativas e epistemologias, imaginar outras realidades possíveis, que forneçam alternativas à violência de um sistema que exaure, subjuga e explora a maioria da população, um sistema onde certas vidas importam e outras são dispensáveis, um sistema que impõe padrões inatingíveis que nos mantém em constante estado de inadequação.
11 Escuto poesia na vida alheia: um processo de criação radiocênica (2017), pesquisa de mestrado no PPGAC da UFRGS com orientação Profa Dra Mirna Spritzer.

12 TODAS NÓS: práticas de intimidade e atuação cênica (2017), pesquisa de mestrado no PPGAC da UFRGS com orientação Profa $\mathrm{Dr}^{\mathrm{a}}$ Patricia Fagundes.

13 (E)terno (2010), disciplina Estágio de Atuação II, graduação em Artes Cênicas Departamento de Arte Dramática da UFRGS com orientação da Profa $\mathrm{Dr}^{\mathrm{a}}$ Luciana Olendzki; Pílula da visibilidade: Maria Scariot Presente! - o processo criativo e feminista de Due Lati Della Campana (2016), pesquisa de mestrado no PPGT/UDESC com orientação Profa Dra Maria Brígida de Miranda. 
Mergulho na memória, em uma época em que eu queria ser pequena.

Pequena para poder caber no mundo. Em alguma medida, estamos dentro deste ambiente onde corpo-beleza-sexo-rendimento-competição traçam as 'regras do jogo' em uma busca por alcançar a representação de padrões historicamente construídos. Você não pode dançar porque é muito grande! Você não pode fazer ginástica olímpica por que é muito grande! Você não é bonita, delicada e/ou por que é grande! Você não cabe aqui por que é muito grande! Você tem tamanho de homem! Você nunca será a primeira da fila! Magra, corpo delineado - 90,60,90 -, estatura mediana, traços suaves, cabelos lisos, loiros, pele branca, bem-humorada, eficiente, uma mulher de sucesso, sem bafo, sem 'asa', sem pelos, sem chulé. (Eu queria ser Paquita ou Garota Verão, mas não era loira e nem magra o suficiente). Eu usava roupas ou sapatos de homem. Não por querer ou gostar, e tudo bem, eu até gostava. Mas também era o que me servia. Eu queria ser magra, para parecer menor e mais leve.

A feminista francesa Virgínia Despentes (2016, p. 11) já nos alertou que é provável que essa mulher idealizada, “[...] essa mulher branca e feliz, cuja imagem nos é esfregada o tempo todo na cara, essa mulher com a qual deveríamos nos esforçar para parecer", na verdade não exista. E precisamos estar atentas para não fortalecer este modelo, ao qual somos continuamente submetidas, de múltiplos modos, desde que nascemos. Assim, uma criação cênica atravessada por discursos feministas envolve algumas perguntas fundamentais: como subverter imagens de subalternização? Como não reforçar o imaginário de violência contra a mulher ao abordar tal violência? Como desconstruir discursos machistas internalizados? É necessário questionar modos de pensamento, práticas criativas, modos de relação e existência. A perspectiva decolonial é uma das vertentes feministas que afirma tais necessidades, destacando cruzamentos entre raça, classe, gênero e sexualidade para pensar as dinâmicas que condicionam a sociedade e nossas existências. Para a artista pesquisadora Camila Bacelar e demais autores (2017, p. 25), os discursos críticos decoloniais e feministas acabam por demandar que "impliquemos nossos corpos e nossos cotidianos num processo diário de descolonização". Aprender a desaprender. 
No que diz respeito à descolonização, o desafio colocado para

as artes da cena é complexo e toca a todas as dimensões do tra-

balho artístico. Implicar nossas práticas criativas em processos de descolonização requer repensar radicalmente não só nossas cenas, poéticas e estéticas, mas principalmente as pedagogias e metodologias de criação artística que as conformam. (BACELAR et al., 2017, p. 26)

Pensar nossas práticas criativas como ato político é uma das linhas que costuram feminismos, corpo e autobiografia, nesta pesquisa e além dela. É também o que levou à definição de uma equipe artística composta predominantemente por mulheres. No primeiro momento do processo criativo, No te pongas flamenca! contou com o apoio de Marcia Metz, colega de mestrado, e Guadalupe Casal, artista com reconhecida trajetória, que estiveram presentes em parte dos ensaios, dialogando, interferindo, escutando. Após definir rumos para a montagem, Juliana convidou Larissa Sanguiné, atriz, encenadora e parceira de trabalho em outras aventuras, para realizar a direção cênica. Victória Sanguiné, atriz, filha de Larissa, se integrou à equipe na mixagem e operação de som. Essa rede de trabalho e afeto contou ainda com lassanã Martins na iluminação, colega do grupo de pesquisa, ${ }^{14}$ onde investiga narrativas inviabilizadas de mulheres, no mundo e na cena.

Mulheres que criam, que tecem suas histórias na cena, na vida, que estabelecem relações com a criação cênica e com a escrita. É preciso propor uma reflexão crítica sobre as estruturas que se apresentam naturalizadas e que inserem um jeito específico de pensar e de narrar. Narrativas que compõem todos os campos, inclusive o do teatro. [...] Por isso, a importância de apresentar criações cênicas desenvolvidas sob a perspectiva de artistas que fizeram ou fazem a cena a partir de suas próprias experiências, as quais vão muito além de histórias particulares. Pelo contrário: suas narrativas servem como forma de identificação para muitas pessoas e como reconhecimento da alteridade. (MARTINS; FAGUNDES, 2018, p. 109)

14 No grupo FRESTA e no projeto teórico-prático Práticas de Encontro: o político na cena contemporânea, que pesquisa a cena como experiência estética, ética e política. 


\section{Narrativas de experiências singulares que remetem a um determinado contexto}

social, compartilhado por muitas; narrativas cênicas que afirmam nossas subjetividades e assim questionam padrões sociais naturalizados, como a violência contra a mulher.
Quando eu tinha 10 anos fui perseguida por uma Kombi, voltando do colégio. Eram dois homens que gritavam coisas pela janela. (sapateado) Quando eu tinha 12, fui abordada por um homem que estava em um carro parado. Ele me convidou para entrar no carro. Quando me aproximei, a janela de trás abriu, um homem de cabelo branco, era ele quem convidava. Eu vestia a farda do colégio. (sapateado e viro de costas). Com 15 o vizinho passou a mão nas minhas costas, por dentro da blusa, eu fiquei paralisada porque ele fez isso enquanto falava com a minha mãe, no corredor do prédio. (viro de frente e pego a saia mostrando as pernas) Quando eu tinha 16 anos fui a uma festa e meu pai me encontrou no final da festa, sentada em uma pedra, virada para o rio, com a meia calça abaixada no meio das pernas e gritando. Alililililililililili Ali ali anda. (viro gritando e pegando a cola, ${ }^{15}$ entra áudio com minha voz falando dos assédios) Eu não lembro. Apagão. Era comum nas festas daquela cidade colocarem 'coisas' na bebida das meninas. Eu estava com um vestido solto no corpo, curto. (Vou repetindo algumas das falas da gravação e sapateio, aumentando a velocidade e a força à medida que o texto é dito) Áudio: Com 18, fui encontrar com o namorado. Era tarde, $23 \mathrm{~h}$, e dia de passe livre. Peguei um ônibus e quando desci um homem veio atrás de mim me empurrou contra uma grade, enfiou a mão embaixo da minha saia. Eu reagi, gritei. Ele foi embora. O guarda do prédio não fez nada. Maldita saia. Ainda aos 18, depois de uma apresentação de flamenco em um bar restaurante em Porto Alegre, um dos garçons me falou 'tem um homem que disse que te dá 100 reais para sentar na mesa dele'. Em uma outra apresentação, para um público de homens na maioria, quando comecei a subir a saia, gritavam “tira, tira, tira”. Eu estava vestida de flamenca, vestido longo, subi a saia até os joelhos. Nesta mesma noite, os homens
15 Vestido (bata) com uma longa cauda (cola), é um instrumento característico do baile flamenco. 
do público ficaram ligando para o quarto das bailarinas. Com 2021.1

19, andando por uma avenida pelas dez da noite, de braço dado com uma amiga tão alta quanto eu, nos jogaram ovos, 'traveco! Algumas vezes, esperando o ônibus, fui abordada por homens em seus carros me convidando para entrar. Acho que era por causa da saia curta. Maldita saia. (Sequência de golpes e largo a cola) Maldita saia! (transição) A gente acostuma, é ‘mimimi'...a gente acostuma.: Até que eu olhei para minha filha. (golpe) Não mexe com ela. Não é mimimi. Não mexe com ela, não mexe com ela, não mexe. (KERSTING, 2019, p. 170-172)

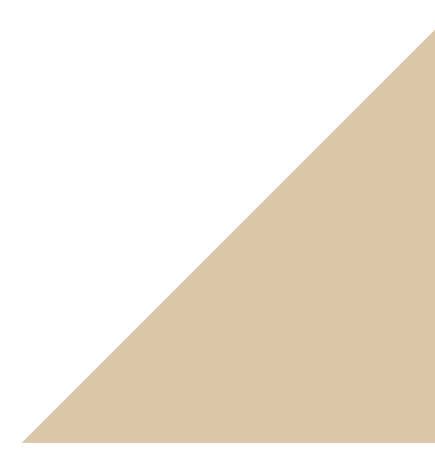

8
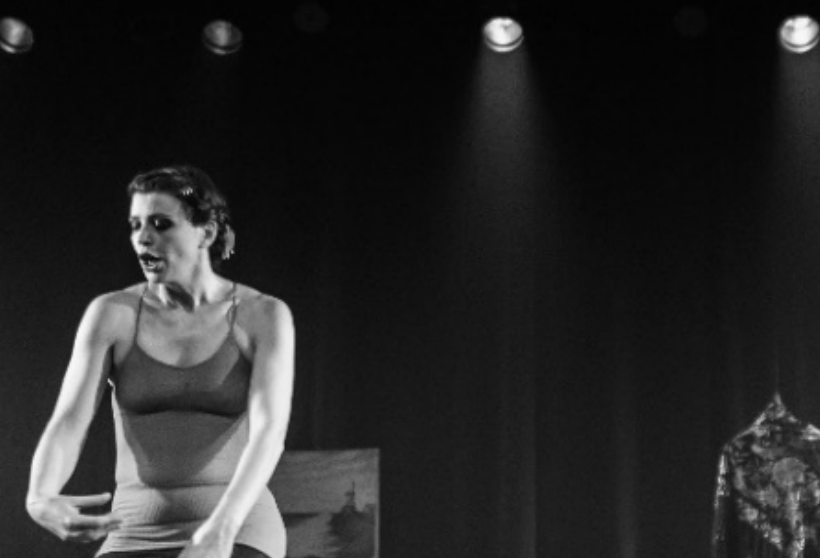

(1) 


\section{PARAFINALIZAR}

Em No te pongas flamenca! teatro e flamenco misturam-se na composição de cenas e na produção de estados, imagens e energias, compassos encarnados de memórias. Palavras, histórias, músicas, sonoridades e movimentos compõem a narrativa autobiográfica; o flamenco e a cena como espaços de exercício de identidades e liberdade encontrados por Juliana, onde seu corpo não-padrão de 1,85 m pode dançar e criar. Nesse mergulho mnemônico atravessado pelos saberes e discursos feministas, a atriz bailaora vai batendo firme e compassadamente os pés no chão, ou sapateia furiosamente em ritmo acelerado enquanto enuncia violências cotidianas e extra cotidianas de uma sociedade machista. Uma mulher que desenha os gestos imponentes do flamenco para denunciar padrões inventados, como a suposta “fragilidade feminina”, ou que golpeando forte no chão alerta: “não mexe com ela!"

A expressão espanhola No te pongas flamenca! significa não fique raivosa, não seja "briguenta”. Como nome do espetáculo, propõe uma afirmação de ser flamenca, artista e mulher, em contraponto ao estereótipo feminino de ser emocionalmente frágil, histérica ou descontrolada; “não se descontrole, não seja histérica! Não reclame, pare de mimimi!". Frente às tantas violências cotidianas do poder, muitas vezes é preciso colocar-se flamenca, sim, protestar com nosso amor e nossa fúria. Ainda é preciso brigar. A expressão também carrega em si a marca de corpo-memória e autobiografia da artista que, junto a produções feministas, potencializaram a construção de uma dramaturgia onde as mulheres estão em evidência. Mulheres comuns que encontraram no cotidiano frestas para existir, que tomam a cena revelando sua rebeldia, contradições e revoltas.

A dramaturgia de No te pongas flamenca! se faz assim de experiências singulares, daquilo que nos passa e nos acontece, daquilo que nos faz. De experiências de vida que ressoam na memória, da memória marcada no corpo, de redes de pensamento sobre nosso viver no mundo, das redes de afeto que nos ajudam a sobreviver e criar. Ao mesmo tempo que é feito de experiência, o próprio fazer teatral é experiência, o processo criativo da cena nos acontece e transforma; o que fazemos nos faz. A criação dramatúrgica em processo presentifica a experiência, palavra encarnada, escrita das próprias narrativas na travessia de risco que supõe a aventura da criação. Escrita da cena, da pesquisa, da vida. 


\section{REFERÊNCIAS}

ALCÂNTARA, C. Formação teatral como criação: narrativas sobre modos de ficcionar a si mesmo. 2012. Tese (Doutorado em Educação) - Faculdade de Educação, Universidade Federal do Rio Grande do Sul, Porto Alegre, 2012.

ALMEIDA, V. F. M. Outras Cassandras e as classes perigosas. ARJ - Art Research Journal: Revista de Pesquisa em Arte, Natal, v. 6, n. 1, p. 1-22, 2019.

BACELAR, C. B.; ALCURE, A. S.; AZEVEDO, M. T. et al. Pedagogias feministas e de(s)coloniais nas artes da vida. Ouvirouver, Uberlândia, v. 13, n. 1, p. 24-39, 2017.

BEAUVOIR, S. O segundo sexo: a experiência vivida. 2. ed. São Paulo: Difusão Europeia do Livro, 1980.

BOGART, A. A preparação do diretor: sete ensaios sobre arte e teatro. São Paulo: Martins fontes, 2011.

CALDEIRA, S. A construção poética de Pina Bausch. Revista Poiésis, Rio de Janeiro, v. 11, n. 16, p. 118-131, 2010.

CARDOSO, T. Treinamento do ator: plano para reinvenção de si. 2009. Dissertação (Mestrado em Artes Cênicas) - Instituto de Artes, Universidade Federal do Rio Grande do Sul, Porto Alegre, 2009.

CARNEIRO, S. Enegrecer o feminismo: a situação da mulher negra na América Latina a partir de uma perspectiva de gênero. In: HOLLANDA, H. B. Pensamento feminista: conceitos fundamentais. Rio de Janeiro: Bazar do Tempo, 2019. p. 313-323.

DESPENTES, V. Teoria king kong. São Paulo: N-1 edições, 2016.

FABRINI, V.; MIRANDA, M. B.; ROMANO, L. Mesa vozes feministas: arte e ativismo. In: CONGRESSO ABRACE, 10., 2018, Natal. Anais [...]. Natal: ABRACE, 2018.

FAGUNDES, P. Composição dramatúrgica: práticas de criação cênica. Cena, Porto Alegre, n. 29, p. 64-77, 2019.

FAGUNDES, P.; MARTINS, I. Escrever como atriz, como mulher. Urdimento, Florianópolis, v. 3, n. 33, p. 98-111, 2018

FER. conferencia "El flamenco en la identidad andaluza" Cristina Cruces Roldán. [S. I.: s. n.], 2013. 1 vídeo (74 min). Publicado pelo canal Flamenco En Red. Disponivel em: https://www.youtube. com/watch?v=-LViDPXqyeY. Acesso em: 28 ago. 2019.

FERNANDES, C. A prática como pesquisa e a abordagem somático performativa. In: CONGRESSO ABRACE, 8., 2014, Belo Horizonte. Anais [...]. Belo Horizonte: UFMG, 2014. p. 1-6. FISCHER-LICHTE, E. The transformative power of performance. London: Routledge, 2008. GROTOWSKI, J. Teatro e ritual. In: GROTOWSKI, J.; POLLASTRELLI, C. (org.). O teatro laboratório de Jerzy Grotowski 1959-1969: textos e materiais de Jerzy Grotowski e Ludwik Flaszen com um escrito de Eugenio Barba. São Paulo: Perspectiva, 2010. p. 119-137.

KERSTING, J. No te pongas flamenca!: corpo-memória de uma atriz bailaora. 2019. Dissertação (Mestrado em Artes Cênicas) - Universidade Federal do Rio Grande do Sul, Porto Alegre, 2019. Disponivel em: https://lume.ufrgs.br/handle/10183/204916. Acesso em: 22 jul. 2020. 
KILOMBA, G. Descolonizando o conhecimento: uma palestra-performance de Grada

Kilomba. MIT SP, São Paulo, 2016. Disponível em: https://joaocamillopenna.files.wordpress. com/2018/05/kilomba-grada-ensinando-atransgredir.pdf. Acesso em: 13 nov. 2018.

LARROSA, J. Tremores: escritos sobre experiência. Belo Horizonte: Autêntica, 2014.

MIRANDA, M. B. Teatros feministas na llha das Bruxas: memórias e "herstory" de práticas teatrais feministas em Florianópolis. In: SEMINÁRIO INTERNACIONAL FAZENDO GÊNERO, 11., Florianópolis, 2017. Anais [...]. Florianópolis: UFSC, 2017. p. 1-12.

SÁNCHEZ, J. A. Dramaturgia en el campo expandido. In: BELLISCO, M.; CIFUENTES, M. J.; ÉCIJA, A. (ed.). Repensar la dramaturgia. Murcia: CENDEAC, 2011. p. 19-37.

TELLES, M. A. A. Breve história do feminismo no Brasil. São Paulo: Brasiliense, 1999.

Patricia Fagundes: é professora associada do Departamento de Arte Dramática e do Programa de Pós Graduação em Artes Cênicas da UFRGS, encenadora, diretora Cia Rústica de Teatro. Juliana Kersting: é atriz bailaora de flamenco e produtora, Mestra e Doutoranda em Artes Cênicas pelo PPGAC-UFRGS. 